\title{
Control System Based on Anode Offgas Recycle for Solid Oxide Fuel Cell System
}

\author{
Shuanghong Li (D), Chengjun Zhan, and Yupu Yang \\ Department of Automation, Key Laboratory of System Control and Information Processing, Ministry of Education, \\ Shanghai Jiao Tong University, Shanghai, China
}

Correspondence should be addressed to Shuanghong Li; lishuanghong1989@163.com

Received 3 December 2017; Accepted 5 February 2018; Published 8 March 2018

Academic Editor: Alessandro Mauro

Copyright (C) 2018 Shuanghong Li et al. This is an open access article distributed under the Creative Commons Attribution License, which permits unrestricted use, distribution, and reproduction in any medium, provided the original work is properly cited.

The conflicting operation objectives between rapid load following and the fuel depletion avoidance as well as the strong interactions between the thermal and electrical parameters make the SOFC system difficult to control. This study focuses on the design of the decoupling control for the thermal and electrical characteristics of the SOFC system through anode offgas recycling (AOR). The decoupling control system can independently manipulate the thermal and electrical parameters, which interact with one another in most cases, such as stack temperatures, burner temperature, system current, and system power. Under the decoupling control scheme, the AOR is taken as a manipulation variable. The burner controller maintains the burner temperature without being affected by abrupt power change. The stack temperature controller properly coordinates with the burner temperature controller to independently modulate the stack thermal parameters. For the electrical problems, the decoupling control scheme shows its superiority over the conventional controller in alleviating rapid load following and fuel depletion avoidance. System-level simulation under a power-changing case is performed to validate the control freedom between the thermal and electrical characteristics as well as the stability, efficiency, and robustness of the novel system control scheme.

\section{Introduction}

Hydrogen-fueled solid oxide fuel cells (SOFC) can directly generate electric power from hydrogen with numerous advantages, such as high electrical efficiency, reduced emissions, and quiet operation as compared with traditional power sources [1-4]. The SOFC system is especially suitable in the structuring of distributed alternative power stations, because it can efficiently produce electricity. Moreover, the quiet operation characteristic associated with the reduced emission feature makes the system appropriate in locating SOFC systems in downtown areas and densely populated regions for residual and commercial loads. Although the SOFC system possesses several advantages, the SOFC system has not reached the commercialization degree because of system durability and reliability problems. Therefore, a control method that not only ensures system safety but also efficiently operates the system must be developed [5-8].

Solid oxide fuel cell (SOFC) modeling is a low-cost method for studying and investigating fuel cells, optimizing and controlling their behavior, enhancing their efficiency and performance, and reducing high installation costs. Some review papers have examined the different aspects of SOFC and reviewed different mathematical modeling studies to aid future researchers in developing $\operatorname{SOFC}[9,10]$. In [11], a 0D mathematical model was introduced to analyze the performance of an SOFC-based microcogenerative power system that was fed by natural gas. The novelty of the proposed approach lies in its ability to accurately reproduce the logic of an on-board control system, which predicts different steady-state operating conditions by taking into account the actual operating ranges imposed by the manufacturer for the main parameters, such as stack temperature. Reference [12] investigated the 2D and 3D numerical modeling of SOFC by employing an accurate and stable fully matrix-inversion-free finite element algorithm. In [13], a new 3D finite element algorithm based on a detailed mathematical model for fuel cells and on the fully explicit artificial compressibility characteristic-based split scheme was employed to effectively and efficiently model the heat and 


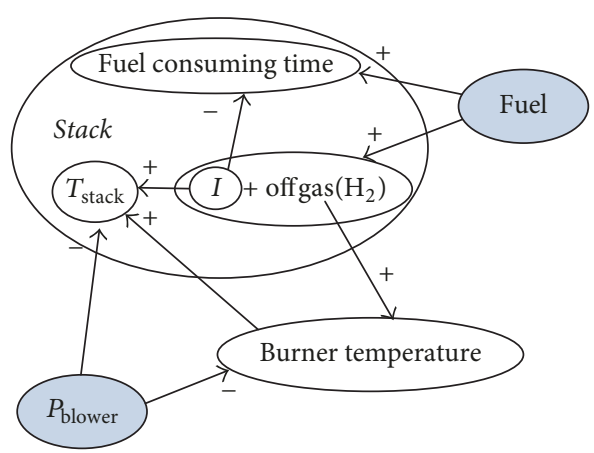

(a) Interactions before decoupling

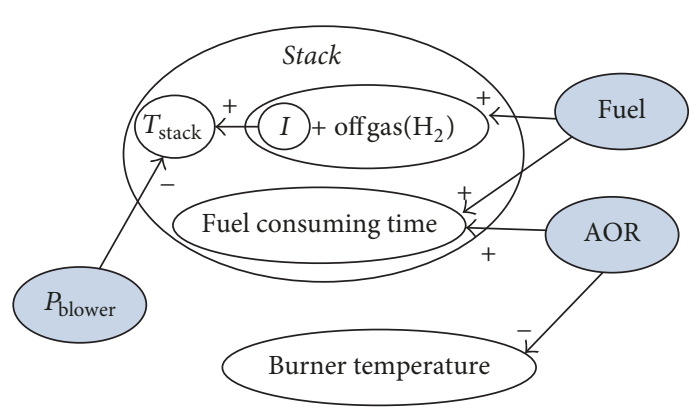

(b) Interactions after decoupling

FIGURE 1: System coupling relationships before and after decoupling control.

mass transport phenomena coupled with electrochemical reactions in SOFC. The calculation results in [14] for the voltage and temperature distributions of a $3 \mathrm{D}$ computational fluid dynamics model were compared with the results of an experimental program with data for an 18-cell stack. This work is among the first to compare physical experiments with a comprehensive SOFC stack model. To perform SOFC measurements, [15] conducted an a priori uncertainty analysis of a cogenerative module based on HT-SOFC, on-board instruments, and meteorological characteristics declared by the manufacturer. Inspired by these studies, this paper examines the problem of an SOFC system based on a model.

In recent years, numerous studies on the control of SOFC systems have been published. Generally, these studies mainly attempted to address three control targets of the SOFC: (1) maintaining a rapid flow of power to address the power demand $[1,2,6-8,16-20]$; (2) keeping the crucial components, such as the stack, burner, and exchanger temperature below the safety operation limits $[5,8,16,21-25]$; and (3) ensuring high levels of fuel utilization and system efficiency $[5,8,21,23,26,27]$. For the optimal operation of the SOFC system, an integral control scheme with rapidness, efficiency, easy application, and robustness must be designed to handle the control targets [28]. However, the strong couplings lead to the difficulty of the control design, which aims to optimally operate the SOFC system, as shown in Figure 1. As a multivariable system, the SOFC has several input and output variables that cross-couple or interact among one another. The characteristic, in which a change in one input affects several outputs, prevents control engineers from designing each input-output control loop independently, as adjusting one controller parameter affects the performance of another and may destabilize the entire system.

Therefore, by designing a decoupling control scheme, the multivariable SOFC system can be simplified to several single-variable systems that have no cross-coupling or interaction among variables, which is critical to SOFC control. Through the application of the decoupling control, each SOFC output variable is affected by only one reference input variable, and then each input-output pair can be controlled by a single-input single-output (SISO) controller, which is considerably easier for control engineering practice and demands less hardware cost as compared with the multivariable control. Wu et al. [29] designed a power decoupling controller for the SOFC-MGT hybrid system by self-tuning proportional-integral derivation (PID) to independently control the SOFC power and MGT power. Zhao et al. [30] developed a control solution based on dynamic disturbance decoupling control for a centrifugal compression system, which is used to supply compressed air to the fuel cell to manipulate the mass flow and pressure. However, to the best of the author's knowledge, no study has attempted to manage the decoupling control of the SOFC's thermal and electrical characteristics, thereby resulting in difficulty in achieving efficient system operation and guaranteeing safety.

The anode offgas recycle (AOR), through which the anode offgas is partially recycled to the anode inlet, has been used in recent research to increase SOFC system efficiency [31-34]. For the hydrogen-fueled SOFC system (Figure 2) decoupling controller designing, the plant output variables are difficult to manage independently because of the lack of control inputs needed to construct the input-output pairs. Therefore, to alleviate this problem in decoupling the interactions between the variables, this study adds the AOR as an independent manipulation variable to design the decoupling control architecture. The AOR is suitable in managing the system-level decoupling control of hydrogen-fueled SOFC because the hydrogen-fueled SOFC without reform reactions requires less heat generated by the burner for system heat self-sustenance, and the AOR can prevent the excessive hydrogen in the offgas from entering the burner to generate useless heat. Although many previous works have employed the AOR to improve system efficiency [31-34], its function in system-level control is first investigated in the current study.

This study aims to decouple the interactions among the thermal and electrical parameters in the hydrogen-fueled SOFC system based on the dynamic SOFC model to simplify the multiple-input multiple-output (MIMO) control system to several SISO control systems, which are suitable for controller development and implementation. By using the AOR-based method, we design the decoupling controller to solve the following problems. 


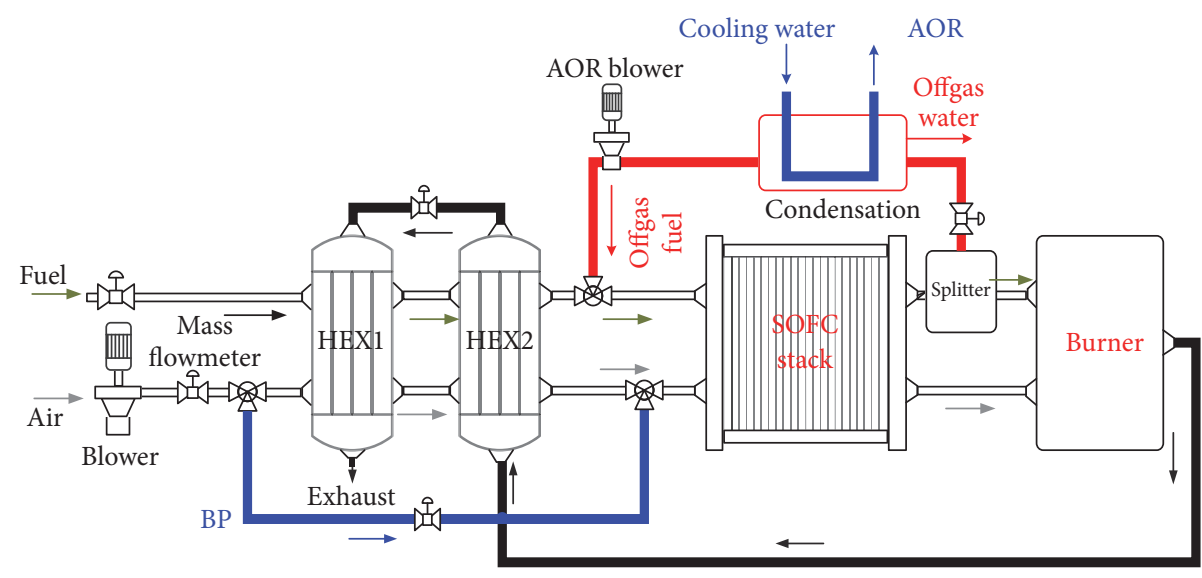

FIGURE 2: SOFC structure with anode offgas recycle.

(1) Decoupling Temperature from Power Changing. The burner temperature can be independently controlled by the AOR without being affected by the fuel flow increase caused by load power changing. The stack temperature can be independently managed without being significantly affected by power fluctuation.

(2) Rapid Load Following and Fuel Depletion Avoidance. The rapid loading capability of the system and the fuel depletion problem, which is limited and caused by the fuel supply time delay, are improved through proper handling of the AOR rate. Given that the AOR structure provides another part of fuel supply with high response speed to the stack, the fuel consumption time increases.

This study provides a helpful reference and example for the development of the control of the hydrogen-fueled SOFC system as well as SOFC with a $\mathrm{MgH}_{2}$ tank, thereby allowing for both the robustness of controller and the feasibility of engineering implementation.

\section{Description of the Studied AOR-SOFC}

The $\mathrm{kW}$-scale SOFC stand-alone system is developed as the platform for the decoupling control design. Special attention is drawn on the system-level thermal and electrical parameter simulation. The SOFC system is modeled based on transportation and conservation principles. The model has been built through many previous efforts $[5,27]$. Given that the focus of this study is system controller design, the dynamic modeling method is briefly introduced. The model runs in a MATLAB/Simulink platform on a computer with $3 \mathrm{GHz}$ and $12 \mathrm{G}$ memory. The $\mathrm{kW}$-scale SOFC stand-alone system model comprises a planar SOFC stack, a burner, and two heat exchangers (Figure 2), in which a special consideration for stack spatial temperature management is conducted by an air bypass manifold around heat exchangers. Particularly, an AOR structure is designed in this system. The SOFC system in this study has the following two characteristics:

(1) For stack temperature gradient along the gas flow direction to be minimized, the gas entering the stack should be preheated although the exchangers using the burner exhaust gas. In this study, another manifold bypassing the exchangers is added to the system whose cold air mixes with the preheated air passing through the main air manifold. Manipulating the flow rate of cold air is an effective way to manage the stack inlet temperature. Therefore, only by controlling both the bypass (BP) ratio and the air flow rate can the stack inlet and outlet temperature be efficiently managed.

(2) The AOR structure is used in the SOFC system: the AOR structure consists of a splitter, condensation, and an AOR blower and mixer. The condensation is the key element in the AOR because it is where the anode offgas is collected, condensed, stored, and transported to the stack by the AOR blower.

Some simplifying assumptions are made to obtain a computationally dynamic model.

(1) All of the gases in the system are ideal gases, and the pressure drop along the channels is neglected.

(2) The gas in the system is assumed to be incompressible.

(3) The system is assumed to be insulated from the system in which no heat is transferred to the environment.

In this section, the stack and thermal dynamic models are introduced first. The configuration and feasibility of the AOR structure is then discussed. Finally, some systemlevel operation parameters are defined for this special SOFC system.

Since the system model is used for control oriented analysis and design, some simplifications are considered for a balance between model details and computational burden. The simplifications consist of a quasi-two-dimensional approach for resolving geometrical features of the system components. This approach discretizes each component in the flow direction and resolves chemical and physical processes, such as electrochemical reaction, heat conduction, and convection. The discretized elements are called nodes. Each node includes two types of control volumes, gas phase and solid phase control volumes, representing the primary elements in the cross-wise direction $[5,16]$. In each control 
volume, only the physical and chemical processes that affect the time scale of interest in the dynamic simulation are taken into account. For instance, electrochemical reaction and the dynamics of burn are assumed to occur at a time scale that is faster than that of interest to the dynamic model; those processes are considered quasi-steadily in the system model.

2.1. Stack Model. In this section, the electrical characteristics which are the most important component in planar type stack are conducted. The single cell voltage is obtained by calculating three polarization voltage losses from the irreversible open circuit voltage:

$$
U_{\text {cell }}=U_{\mathrm{OCV}}-U_{\text {loss }}=U_{\mathrm{OCV}}-U_{\mathrm{ohm}}-U_{\mathrm{act}}-U_{\text {con }},
$$

where $U_{\text {cell }}$ is the single cell output voltage, $U_{\mathrm{OCV}}$ is the irreversible open circuit voltage (OCV) that is also called Nernst voltage, $U_{\mathrm{ohm}}$ is the ohmic polarization voltage loss, $U_{\text {act }}$ is the activation polarization voltage loss, $U_{\text {con }}$ is the concentration voltage loss.

The irreversible open circuit voltage (OCV) is expressed as follows:

$$
U_{\mathrm{OCV}}=E^{0}+\frac{R T_{\mathrm{PEN}}}{2 F} \ln \left(\frac{P_{\mathrm{H}_{2}} P_{\mathrm{O}_{2}}{ }^{0.5}}{P_{\mathrm{H}_{2} \mathrm{O}}}\right) .
$$

According to the Ohm's law the ohmic polarization voltage loss can be calculated by current density and ohmic resistance:

$$
U_{\mathrm{ohm}}=i R_{\mathrm{ohm}}=i T_{\mathrm{PEN}} e^{a_{1} / T_{\mathrm{PEN}}+a_{0}} .
$$

The activation and concentration voltage loss can be described as follows:

$$
\begin{aligned}
U_{\mathrm{act}, a} & =\frac{2 R T}{n_{e} F} \sinh ^{-1}\left(\frac{i}{2 i_{o a}}\right), \\
U_{\mathrm{act}, c} & =\frac{2 R T}{n_{e} F} \sinh ^{-1}\left(\frac{i}{2 i_{o c}}\right), \\
U_{\text {con }} & =\frac{R T}{n_{e} F} \ln \left[1-\frac{i}{i_{L} A}\right] .
\end{aligned}
$$

Those polarization voltage losses are complicated chemical and physical process concerning with temperature, pressure, and current; consequently, the expression would not be of the same form. According to the Butler-Volmer equation, the current density is

$$
i=i_{0}\left\{\exp \left(\alpha \frac{n_{e} F U_{\mathrm{act}}}{R T}\right)-\exp \left(-(1-\alpha) \frac{n_{e} F U_{\mathrm{act}}}{R T}\right)\right\},
$$

where the $\alpha$ is the transfer coefficient, $i_{0}$ is the exchange current density, $n$ is the electrons transferred per reaction, and $U_{\text {act }}$ is the activation polarization.

2.2. Thermal Dynamic Equations. The model emulates the chemical and physical reactions in the SOFC system, such as electrochemical reaction, heat conduction, and convection. In particular, the most important part is the stack which will be individually described in the next section. The system variables such as temperature, molar flow rates, and mole fractions are described by energy, mass, and species conservation laws.
2.2.1. Solid Phase Control Volume. The dynamic solid-state energy conservation equation is in the general form:

$$
\rho_{s} V_{s} C_{s} \frac{d T_{s}}{d t}=\sum \frac{d Q_{\text {in }, s}}{d t}+\frac{d Q_{\text {react }}}{d t}-\frac{d W_{\text {out }}}{d t},
$$

where $\rho_{s}, V_{s}$, and $C_{s}$ denote the density, volume, and specific heat capacity of each solid control volume, respectively.

Conduction and convection heat transfer between the solid phase control volumes are determined by Fourier's law and Newton's law. Fourier's law is utilized to capture conduction heat transfer among solid phase control volumes using the temperature of each control volume:

$$
\frac{d Q_{\text {cond }}}{d t}=\frac{S_{\text {area }} \cdot k_{s s} \cdot\left(T_{2}-T_{1}\right)}{L} .
$$

Newton's law is used to calculate convection heat transfer between solid and gas phase control volumes:

$$
\frac{d Q_{\text {conv }}}{d t}=S_{\text {area }} \cdot h_{g s} \cdot\left(T_{2}-T_{1}\right) \text {. }
$$

2.2.2. Gas Phase Control Volume. The conservation of energy equation of the gas is as follows:

$$
N C_{v} \frac{d T}{d t}=\frac{d\left(N_{\text {in }}\right)}{d t} h_{\text {in }}-\frac{d\left(N_{\text {out }}\right)}{d t} h_{\text {out }}+\sum \frac{d\left(Q_{\text {in }}\right)}{d t},
$$

where $N$ is control volume mole number, $C_{v}$ is constant volume specific heat capacity of the gas mixture, $N_{\text {in }}$ and $N_{\text {out }}$ represent molar flow rate entering or exiting the control volume, $h_{\text {in }}$ and $h_{\text {out }}$ are enthalpy of the gas mixture entering or exiting the control volume, $Q_{\text {in }}$ is heat transfer entering control volume.

The constant volume specific heat capacity of gas mixture $C_{v}$ is calculated as follows:

$$
C_{v}=\sum X_{i} C_{p, i}(T)-R, \quad i \in\left\{\mathrm{H}_{2}, \mathrm{O}_{2}, \mathrm{H}_{2} \mathrm{O}, \mathrm{N}_{2}\right\}
$$

where $R$ is the universal gas constant, $X_{i}$ is mole fraction of species $i, C_{p, i}(T)$ is the constant pressure specific heat capacity.

The corresponding exit species mole fractions are calculated by the species conservation equation:

$$
\begin{aligned}
N \frac{d\left(X_{i}\right)}{d t} & =\frac{d\left(N_{\text {in }}\right)}{d t} X_{i, \text { in }}-\frac{d\left(N_{\text {out }}\right)}{d t} X_{i, \text { out }}+R_{i}, \\
R_{\mathrm{H}_{2}} & =-\frac{i S_{\text {node }}}{F},
\end{aligned}
$$

where $R_{i}$ is the reaction rate of individual species $i$ and the $R_{\mathrm{H}_{2}}$ is the reaction rate of $\mathrm{H}_{2}$. The exit molar flow rate is determined from the mass conservation equation:

$$
\frac{d\left(N_{\text {out }}\right)}{d t}=\frac{d\left(N_{\text {in }}\right)}{d t}+\sum R_{i}
$$


TABLE 1: Comparison between the model and experiments.

\begin{tabular}{|c|c|c|c|c|c|c|}
\hline \multirow[b]{3}{*}{ Cell } & \multicolumn{3}{|c|}{$5000 \mathrm{~W}$} & \multicolumn{3}{|c|}{$3500 \mathrm{~W}$} \\
\hline & \multirow{2}{*}{$\begin{array}{c}\text { Model } \\
130\end{array}$} & \multicolumn{2}{|c|}{ Experiments } & \multirow{2}{*}{$\begin{array}{c}\text { Model } \\
130\end{array}$} & \multicolumn{2}{|c|}{ Experiments } \\
\hline & & 24 & 22 & & 24 & 22 \\
\hline$P_{\text {out }}[\mathrm{W}]$ & 5000 & 923 & 846 & 3500 & 646 & 592 \\
\hline$V_{\text {cell }}[\mathrm{V}]$ & 0.650 & 0.681 & 0.639 & 0.800 & 0.801 & 0.768 \\
\hline$I_{\text {stack }}[\mathrm{A}]$ & 59.17 & 56.54 & 60.02 & 33.65 & 33.62 & 34.99 \\
\hline$T_{\text {Stack }}[\mathrm{K}]$ & 1021 & 1023 & 1023 & 1006 & 1023 & 1023 \\
\hline$T_{\text {Air }}[\mathrm{K}]$ & 912 & 923 & 923 & 937 & 923 & 923 \\
\hline
\end{tabular}
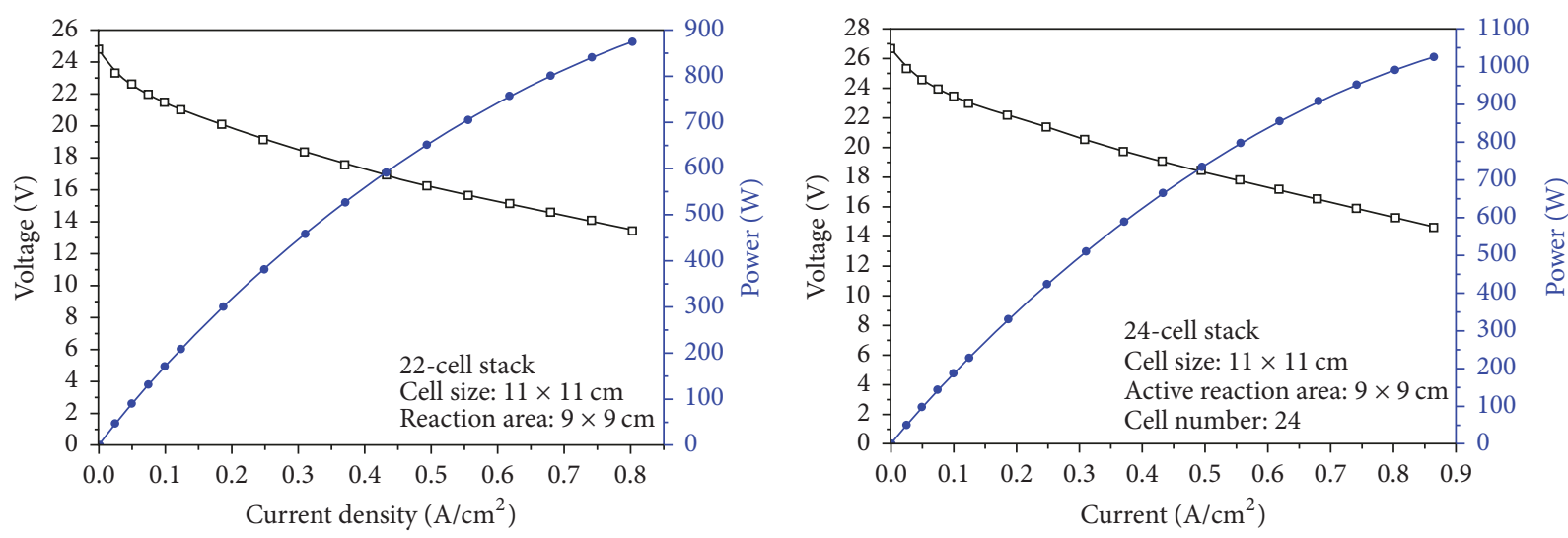

FIGURE 3: Stack testing data.

2.3. Model Validation. All the component submodels in the system model are built based on the mass and energy conservation law. All the model parameters are the same with the actual equipment to ensure the reliability of the SOFC system model. However, due to the influence of various factors and the existence of errors in the actual system, there will be a certain gap between the theoretical model and the actual system. In order to ensure the correctness of the system model building method, it is necessary to carry out the necessary experimental verification to fully demonstrate that the system model can describe the working characteristics of the real physical system. The accuracy of the model is of great significance to the development and design of practical system.

To collect experimental data on the stack, two units were assembled in our laboratory, including 22 cells and 24 cells of $11 * 11 \mathrm{~cm}$ size battery with $9 * 9 \mathrm{~cm}$ reaction area for $1 \mathrm{~kW}$ power supply. The stacks are tested with excess air and hydrogen in a constant temperature reheating furnace. The average operating temperature of the stack is $750^{\circ} \mathrm{C}$ and the gas temperature at the entrance of the stack is $650^{\circ} \mathrm{C}$. The electrical properties of the two stacks are shown in Figure 3. Although the object of this study is the $5 \mathrm{~kW}$ SOFC system, the stack consists of 130 battery chips with the same performance, which can be regarded as five $1 \mathrm{~kW}$ stacks in series. The experimental data of $1 \mathrm{~kW}$ stack can be obtained and compared with the simulation data by scaling the operating points of 130 batteries to 22 and 24 batteries. The comparison between the model and the testing data are shown in Table 1.
2.4. Configuration and Feasibility of the AOR Structure. In this decoupling control-based study, three functions are demanded for the AOR structure to decouple the interactions and manage load-following problems:

(1) Limit the amount of fuel entering the burner.

(2) Safely and efficiently recycle excessive offgas fuel to the stack.

(3) Act as a buffer between the fuel consumption and fuel supply by storing some fuel in the AOR structure to supply the stack when needed.

2.4.1. AOR Configuration. Different recycle structures, such as gas recirculation ejector and blowers, have been used in recent studies to increase the power output and system efficiency. The reformer does not exist in the hydrogen-fueled SOFC system; therefore, a condensation is needed to remove the water gas from the offgas [31]. As shown in Figure 4, the AOR structure consists of a splitter, condensation, and an AOR blower and mixer. The condensation is the key element in the AOR where the anode offgas is collected, condensed, stored, and transported to the stack by the AOR blower. The splitter forces part of the offgas to enter the recirculation pipeline. During such time, the offgas contains $\mathrm{H}_{2}$, which is needed to reenter the stack, and steam, which should be removed. Condensation is utilized to remove $\mathrm{H}_{2} \mathrm{O}$ and store $\mathrm{H}_{2}$ in the AOR structure. The function of the condensation is to remove the water gas down to $333 \mathrm{~K}\left(60^{\circ} \mathrm{C}\right)$ through the cooling water. The offgas only keeps the $\mathrm{H}_{2}$, which is stored in the condensation. The mixer is utilized to mix the cold and hot fuel and maintain the anode pressure. 


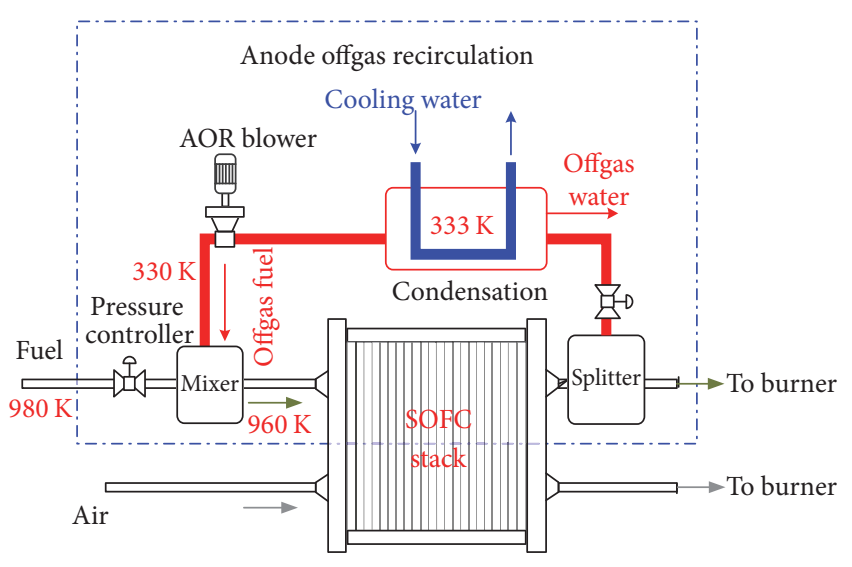

FIgURE 4: The anode offgas recycle structure.

2.4.2. AOR Feasibility. In this study, the AOR structure is designed to recycle the hydrogen to the stack inlet and limit the excessive fuel entering the burner, which generates useless high temperature. The feasibility of the proposed AOR structure aims to address four issues.

(1) Offgas Blower Power. The air supplied to the SOFC stack is significantly larger, usually more than five times that of the fuel entering the system $[4,27]$. Thus, the air blower accounts for most of the parasitic loss, and the AOR blower power loss does not largely increase the power loss and decrease the system efficiency.

(2) Anode Pressure Controller. The offgas blower sends the offgas fuel to the mixer to mix with the primary fuel supply by a pressure controller. The pressure controller maintains the stack inlet pressure by manipulating the fuel flow valve.

(3) Condensation Volume. The condensation stores some hydrogen, thereby making the stack less sensitive to the abrupt load changes because the fuel in the condensation can be blown into the stack to supply the fuel supply delay period (in this study, the duration is $3 \mathrm{~s}$ ). If we suppose that the largest load change is $5 \mathrm{~kW}$ and the fuel utilization is $80 \%$, then the volume should be more than $6 \mathrm{~L}$. At the system startup period, the AOR should be open to fill the condensation with sufficient fuel used when the load abruptly increases, and the fuel can be replenished when the load decreases.

(4) Stack Temperature. The condensation cools the offgas down to $333 \mathrm{~K}$ to remove the $\mathrm{H}_{2} \mathrm{O}$ from the gas. Before the offgas fuel enters the stack, the mixer is applied to prevent the cold fuel gas directly entering the stack from negatively affecting the stack performance. Otherwise, given that the air flow rate is considerably larger than the fuel flow rate, the stack temperature is mainly affected by the air flow rate, and the fuel temperature fluctuation caused by AOR can be regarded as external disturbance, which can be handled by the stack controller, which will be discussed in the next section.

2.5. Operation Parameters. To effectively manage the systemlevel parameters, some operation parameters should be defined in this section, including fuel utilization (FU), bypass ratio (BP), and system efficiency (SE) $[4,9,20]$. Particularly, the anode offgas recycle ratio (AORR) should be defined to effectively manage the SOFC thermal and electrical parameters, which will result in the SE decrease as compared with the SOFC system without AOR. The operating parameters are defined as follows:

$$
\begin{aligned}
\mathrm{FU} & =\frac{\text { fuel consumed in stack }}{\text { fuel entering the stack }}=\frac{n I}{2 F\left(d N_{\mathrm{H}_{2}} / d t\right)}, \\
\mathrm{SE} & =\frac{\text { SOFC power }}{\text { stack power }}=\frac{P_{\text {stack }}-P_{\text {blower }}-P_{\text {offgas,blower }}}{P_{\text {stack }}}, \\
\mathrm{BP} & =\frac{\text { air through bypass manifold }}{\text { air through main manifold }} \\
& =\frac{d\left(N_{\text {air,bypass EX }}\right) / d t}{d\left(N_{\text {air }}\right) / d t} .
\end{aligned}
$$

The AORR is the most important variable in the AOR structure. The recycle rate is defined as the molar fraction of the anode offgas that is recycled.

$$
\text { AORR }=\frac{\text { fuel recycling rate }}{\text { anode offgas rate }}=\frac{d\left(N_{\text {recycle }}\right) / d t}{d\left(N_{\text {offgas }}\right) / d t} .
$$

The AORR refers to the ratio of the recycled gas in the entire offgas.

\section{Decoupling Control Scheme}

In this section, the decoupling control scheme of the SOFC system is developed with the help of AOR to simplify the multivariable system to several single-variable systems. In each single-variable system, the output variables are controlled by one manipulation variable. Given that single-variable control is considerably easier than multivariable control, the decoupling control is especially appropriate for SOFC control engineering practice.

3.1. Control Objectives and Variable Parings. The proper control variable pairings for the MIMO system, SOFC system in this context, must be selected prior to the design and implementation of the decoupling controller. The selection of the proper control variable pairing will determine the inputoutput (IO) pair; then the output variable can be controlled by the input reference variable through the implementation of the SISO controller. All of the SISO controllers in the decoupling control scheme are PID-based controllers. Given its simple structure and good performance in engineering practice, the PID controller is suitable for handling complex SOFC systems with robustness and stability $[9,27]$.

In this study, the voltage is kept at a constant value, and the fuel flow and current are manipulated to control the power. For the electrical parameter, the power can be independently controlled by the current through the implementation of electronic devices, such as the DC/DC (DC/AC) converter: 
TABLE 2: Control variable pairings.

\begin{tabular}{lc}
\hline Manipulate variables (MV) & Control variables $(\mathrm{CV})$ \\
\hline Current & Power \\
Air flow & Stack inlet $T$ \\
Air bypass ratio (BP) & Stack outlet $T$ \\
AORR & Burner $T$ \\
\hline
\end{tabular}

(1) By manipulating the current, the system power can meet the demand $[4-8,16,27]$.

(2) By modulating the fuel flow, the FU is maintained and the current is supplied $[4,27]$.

(3) Limiting the current ensures that the voltage remains at a safe value to prevent the fuel from depleting in the stack $[9,35]$.

For the electrical parameter, the stack inlet temperature, stack outlet temperature, and burner temperature can be independently controlled.

(4) The air flow rate and BP can be manipulated to maintain the stack operation temperature $[4,16,27]$.

(5) The AOR acting as a manipulation variable is the key point to decoupling the interaction of the thermal and electrical parameters. The AORR is used to independently control the burner temperature without being affected by the power fluctuation. All the control variables can be found in Table 2.

The implementation of the selected control variable pairings and the decoupling design are addressed in the following sections.

3.2. Stack Temperature Control. The stack temperature should be kept as the highest priority because the purpose of the SOFC is to supply electricity through electrochemical reaction in the stack. Thus, the safety of the stack is crucial in fuel cell operation. For the SOFC to rapidly and efficiently supply current, its stack temperature must be maintained at a constant level, which will help in strictly controlling the stack thermal gradients and transients. However, several disturbances, including electrochemical reaction heat oscillation and exchanger preheat fluctuation, hamper the stack temperature stabilization.

In this section, the stack temperature controller is designed. The thermal response time has been discussed in [9], in which the thermal response, by manipulating the air flow rate, is more rapid than the inherent thermal response of the stack; thus, the controller can effectively and rapidly manage the stack inlet and outlet temperature. Given that the blower response is significantly faster than the stack thermal response, the air flow can effectively manage the stack temperature. According to the safety requirement, the stack inlet and outlet temperature should be closely maintained near the optimal value (960 and 1,050 K), respectively, during the transient operation period. The stack temperature fluctuation magnitude should be maintained at less than $10 \mathrm{~K}$ around the optimal value (OV).

A feedback control system is designed based on the selected control variable pairings, as shown in Figure 5. Two independent feedback loops are employed to achieve

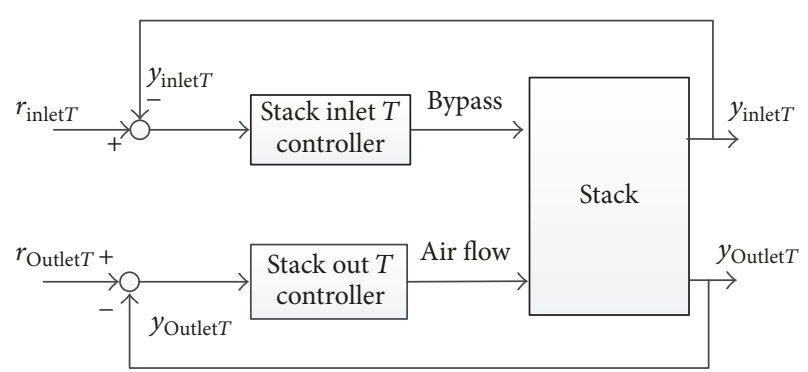

FiguRE 5: Stack temperature controller.

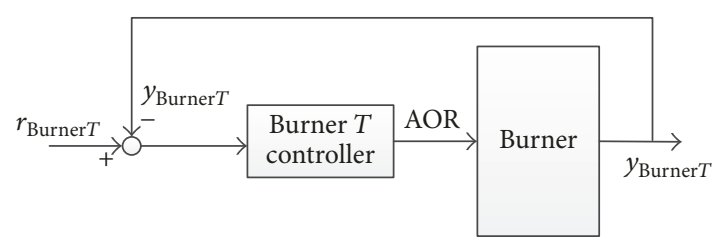

FIGURE 6: New control structure to decouple the burner temperature and the system power: AOR-based independent burner controller.

rapid temperature management. Only when the stack temperature is managed well, can the stack efficiently provide electricity. Given the coupling between the thermal and electrical parameters, the stack inlet temperature cannot be easily managed without affecting the system power. Thus, the stack temperature controller should cooperate with other controllers not only to maintain the system temperature but also to efficiently provide electricity.

3.3. Burner Temperature Control. This section discusses the implementation of the AOR to control the burner temperature without being influenced by electrical parameters. The burner temperature, especially the gas phase temperature, should be maintained because the exhausted gas entering the heat exchangers may negatively affect the stabilization of the stack temperature and the material durability of the burner.

The AOR-based controller contains two parts, namely, burner controller and fuel depletion controller, as shown in Figure 6. In this section, only the burner temperature control actuation is introduced. To maintain the burner temperature $\left(y_{\text {BurnerT }}\right)$, the AOR controls the fuel entering burner, and the excess fuel is recycled to the stack inlet. The fuel flow entering the stack must be decreased because a safe level of stack pressure needs to be maintained. The AOR control actuation in power-level control will be studied in the following section.

3.4. Power Control. For the power control, the voltage is maintained at a constant optimal value, and the power demand can be satisfied by manipulating the stack current using power electronic devices, such as a DC/DC or DC/AC converter. At the same time, as a manipulation variable, the current should be supplied by the fuel. Sufficient fuel must be fed to the stack to avoid fuel depletion and anode reoxidation. The fuel depletion problem should be avoided because it will oxidize the anode material and largely damage the ability to generate fuel cell electricity. 


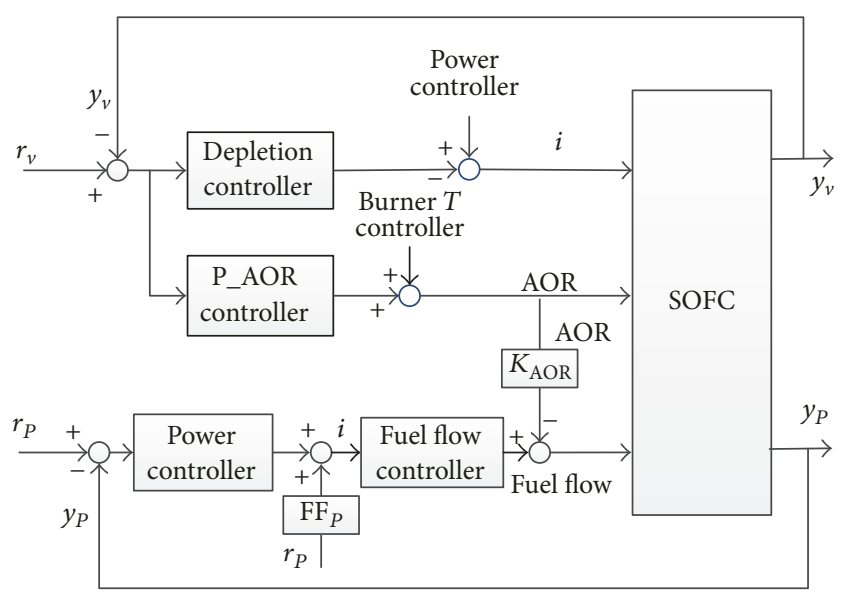

FIGURE 7: Electrical characteristics controller: depletion controller and power controller.

The fuel supply delay results in the fuel depletion problem and leads to limitation of the load-following ability. The abrupt load increase will result in the stack fuel deficiency period because of the fuel supply delay. The fuel contained in the anode compartment will be consumed during that period. To avoid the fuel depletion, sufficient hydrogen must remain in the stack. As analyzed in Section 2, the fuel stored in the AOR condensation supplies the fuel deficiency period to the stack by the actuation of the AOR blower. Thus, the AOR structure can be regarded as an expansion of the stack compartment. Based on the analysis in [16], increasing the stack compartment size makes the stack less sensitive to the abrupt load change. The fuel contained in the condensation can be replenished when the load decreases. The excessive fuel, which previously enters the burner, is then recycled by the AOR to the condensation, which serves as a fuel supply buffer for the abrupt load changes.

The power control scheme consists of four controllers: depletion controller, AOR controller power actuator part (P_AOR controller), power controller, and fuel flow controller. For the depletion controller, to ensure that the hydrogen is not depleted in the stack, the current should be limited to keep the voltage from dropping. The fuel depletion controller is shown in Figure 7. The AOR controller power actuator part (P_AOR controller) is utilized to blow fuel contained in the AOR structure into the stack. The voltage decreases indicate that the fuel concentration in the stack decreases. For the power controller, the current is used to control the power demand, while the fuel flow should be sufficiently supplied by the fuel flow controller.

As shown in Figure 7, the fuel depletion control manages the voltage through the manipulation of the current by feedback (depletion controller). When the voltage $\left(y_{v}\right)$ decreases and is smaller than the reference voltage $\left(r_{v}\right)$, then the $i$ should be lower to decrease the fuel consumption. At the same time, the AOR rate is increased (P_AOR controller) to blow the fuel contained in the AOR condensation tank to the stack satisfying the fuel demand as well as the loadfollowing demand rapidly. The power is controlled by the

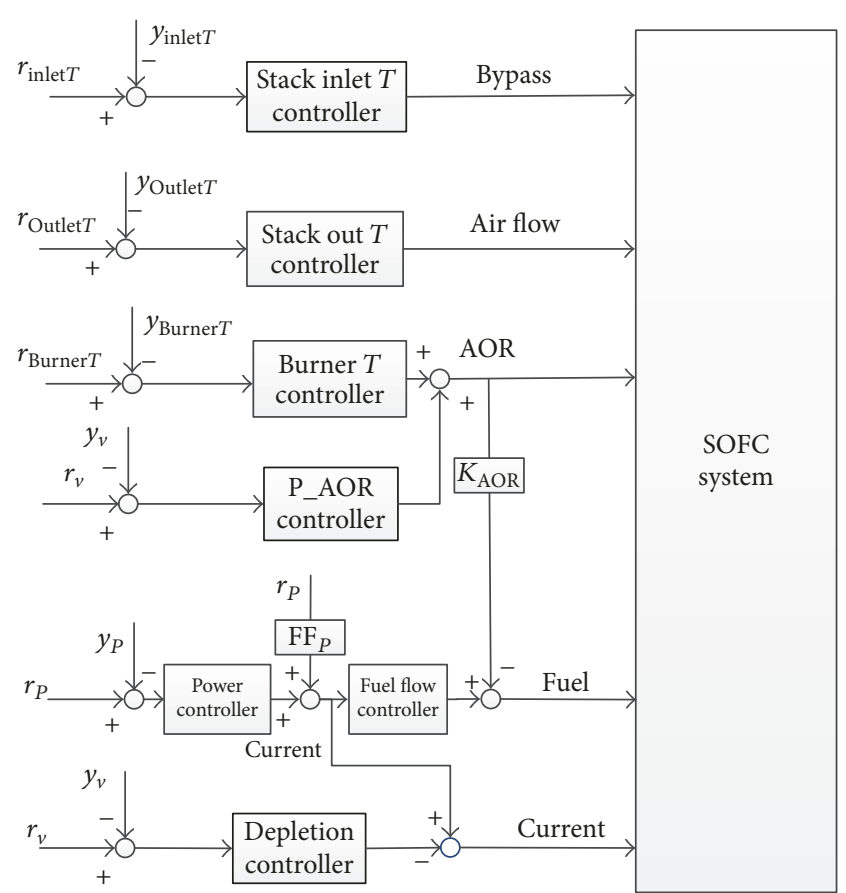

FIGURE 8: Integrate decoupling control.

power feedback (power controller) and the feedforward controller $\left(\mathrm{FF}_{P}\right)$ through the manipulation of the current $(i)$. The AOR feedforward controller $\left(K_{\mathrm{AOR}}\right)$ helps in maintaining the stack fuel pressure by slightly decreasing the fuel flow. The AOR helps in preventing the fuel cell voltage from dropping to a low level, which ensures enough fuel in the anode compartment by enlarging the stack fuel consumption time. The fuel tank in the AOR structure can be regarded as one part of the stack aside from the second fuel supply element.

3.5. Decoupling Control Overview. To demonstrate the relationship of the control inputs and the outputs, the integrated decoupling control scheme is shown in Figure 8. The controller consists of six parts, namely, stack controller, burner temperature controller, $\mathrm{P} \_$AOR controller, power controller, depletion controller, and fuel flow controller. All the control inputs and outputs should be guaranteed within the operation range.

The stack controller manages the BP ratio and air flow to manipulate the stack inlet and outlet temperature, respectively. The burner temperature is managed by the AORR by controlling the fuel entering it. The P_AOR controller also manages the AORR to add the fuel to the stack when the voltage decreases. The fuel depletion controller decreases the current to prevent the voltage from dropping significantly. The power controller manages the system power following the demand rapidly by manipulating the fuel flow rate. The electrical characteristic controller simultaneously handles the rapid load following and the fuel depletion. Moreover, the system-level thermal parameters, such as the stack temperature and the burner temperature, are not influenced by the power changes. Therefore, under the control of the 
TABLE 3: Control parameters.

(1) Stack inlet $T$ control

$K_{p} 2.1 \quad K_{i} 0.61$

(2) Stack outlet $T$ control

$K_{p} 0.3 \quad K_{i} 0.001$

(3) Burner $T$ control

$K_{p} 0.8 \quad K_{i} 0 \quad K_{d} 0.3$

(4) Power control

$K_{p} 0.000016 \quad K_{i} 0.000002 \quad K_{d} 0.000005 \quad K_{\mathrm{AOR}} 0.12$

$\mathrm{FF}_{P} 0.00002$

(5) Depletion control

$K_{P} 1.2 \quad K_{i} 0.01 \quad \mathrm{FF}_{i} 0.024$

(6) Fuel flow control

$K_{P} 0.21 \quad K_{i} 0.012$

decoupling controller, the interactions among the thermal and electrical characteristics can be decoupled.

\section{Simulation Results}

This section performs time-domain simulation of the studied AOR-SOFC and the performance of the decoupling control.

All of the SISO controllers in the decoupling control scheme are PID-based controllers due to their simple structure and good performance in engineering practice with robustness and stability. The control parameters of the decoupling control system, as shown in Table 3, are tuned by the Ziegler-Nichols tuning method, which is suitable for engineering practice. To evaluate the performance of the decoupling controller, especially the load-following ability and system temperature independent control, a powerchanging case is set. This case assumes that the power demand rapidly changes from $3,500 \mathrm{~W}$ to $4,500 \mathrm{~W}$ and then decreases to $4,000 \mathrm{~W}$. System power responses under the control of both the conventional controller and the decoupling controller are shown in the following sections. The decoupling performance is assessed from four aspects: power load-tracking characteristics, burner temperature, stack temperature, and systemlevel operation parameters, namely, fuel utilization (FU) and system efficiency (SE). In this study, the conventional control is the system-level control without the AOR control actuation, which consists of the stack controller, power controller, fuel flow controller, and depletion controller. The conventional control and the decoupling control parameters are the same, as shown in Table 2.

4.1. Power Load-Tracking Characteristics. The power load tracking characteristics are shown in Figure 8. When $0<$ $t<100 \mathrm{~s}$, the power fluctuates because the SOFC needs time to start up from 0 to $3,500 \mathrm{~W}$. When at $t=1,000 \mathrm{~s}$, the power suddenly rises from $3,500 \mathrm{~W}$ to $4,500 \mathrm{~W}$. Both the conventional and decoupling controller manipulate the system to follow the demand. Figure 9(b) shows the local information of the load-following increase. Figure 10 shows the control actuation of the power controller.
The AOR blows the fuel in the condensation into the stack to supply the abrupt load increase, as shown in Figure 10. However, when at $t=1,020 \mathrm{~s}$, the system power stagnates because the depletion controller decreases the current to avoid stack fuel depletion. After several seconds, the fuel from the fuel source reaches the stack to supply sufficient fuel to the current, thereby causing the power to increase again. The conventional control makes the excessive fuel flow rate increase at the power increase, which may cause useless fuel to enter the burner. Figure 9(c) shows that when $t=2,000 \mathrm{~s}$, the power demand decreases from $4,500 \mathrm{~W}$ to $4,000 \mathrm{~W}$. The excessive fuel is blown by the AOR blower from the stack outlet into the AOR to fill the condensation. As a result, the power under the control of the decoupling controller decreases rapidly to the reference power.

Remark 1. The decoupling controller is better than the conventional controller in the power load following and fuel depletion avoidance because the AOR decreases the fuel deficiency period and makes the fuel supply less sensitive to the power variations. The convergence rate of the AOR controller is faster than the controller without AOR shown in Figures 9(b) and 9(c). As the power fluctuates, the AOR controller takes about $50 \mathrm{~s}$ to reach the demand value while the controller without AOR takes about $100 \mathrm{~s}$. That is because when the power demand increases, the AOR recycles fuel in the offgas and transports it to stack again. The fuel intially contained in AOR will enter the stack quickly. Therefore, the power response speed of the AOR controller will be higher than the controller without AOR. For the power decrease condition, the AOR recycle blower helps to decrease the excessive fuel concentration in stack, so the power decrease speed is higher than the traditional controller.

4.2. Burner Temperature. The burner temperature dynamic response during system power changes is shown in Figure 11. The conventional controller causes a large temperature fluctuation, which may damage the burner and cause oscillation in the exchangers and stack temperatures. The AOR-based burner temperature controller maintains the burner temperature by limiting the fuel flow into the burner, as shown in Figure 12. Although the power and fuel flow rate change, the fuel to the burner is nearly maintained at a stable value by the decoupling controller, while the conventional control sends excessive fuel to the burner.

The temperature dynamic responses under the AOR controller are shown in Figure 13. When the power increases, more fuel is consumed in stack to generate current and the heat generated in stack will increase; then less heat will be generated in burner. Therefore, the heat transport to the heat exchanger will decrease. When the power increase, the excessive fuel entering the stack will be recycled, so the burner and the exchangers temperature will not largely change.

4.3. Stack Temperature. Figure 14 shows the stack inlet and outlet temperature under two controllers. The stack outlet temperatures are maintained within $10 \mathrm{~K}$. For the stack inlet temperature, the decoupling controller causes a $10 \mathrm{~K}$ decrease because the AOR sends cold ( $333 \mathrm{~K})$ fuel to the stack inlet. 


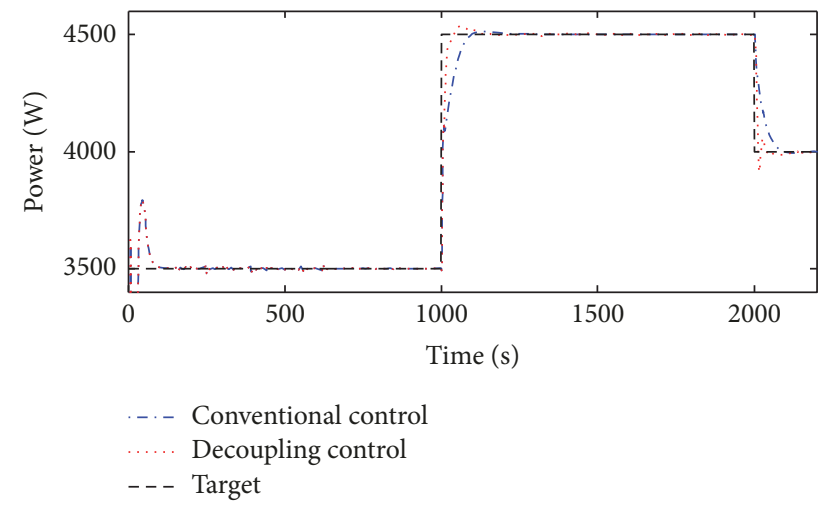

(a)

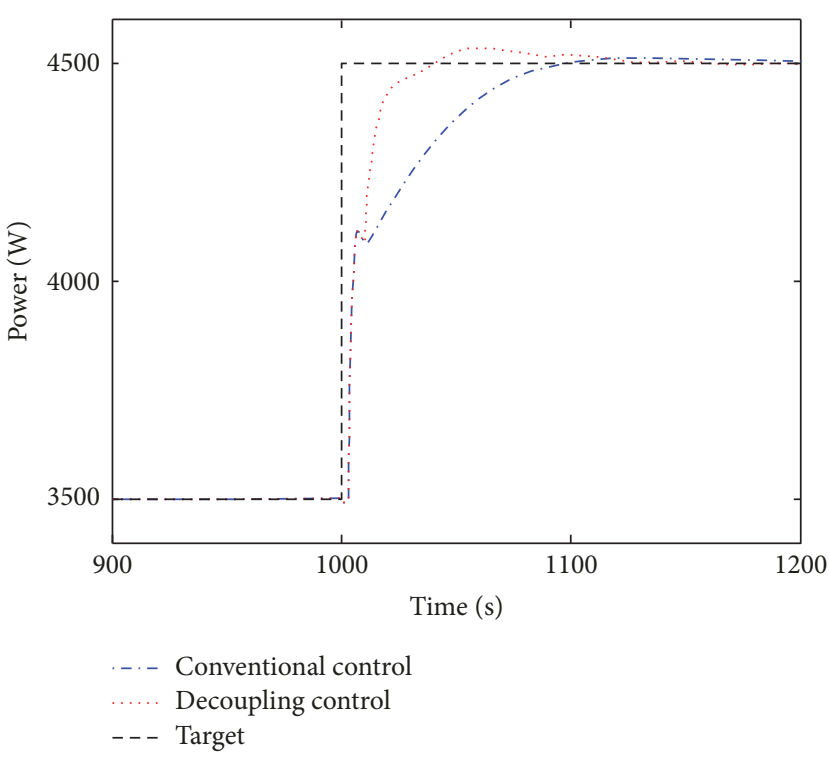

(b)

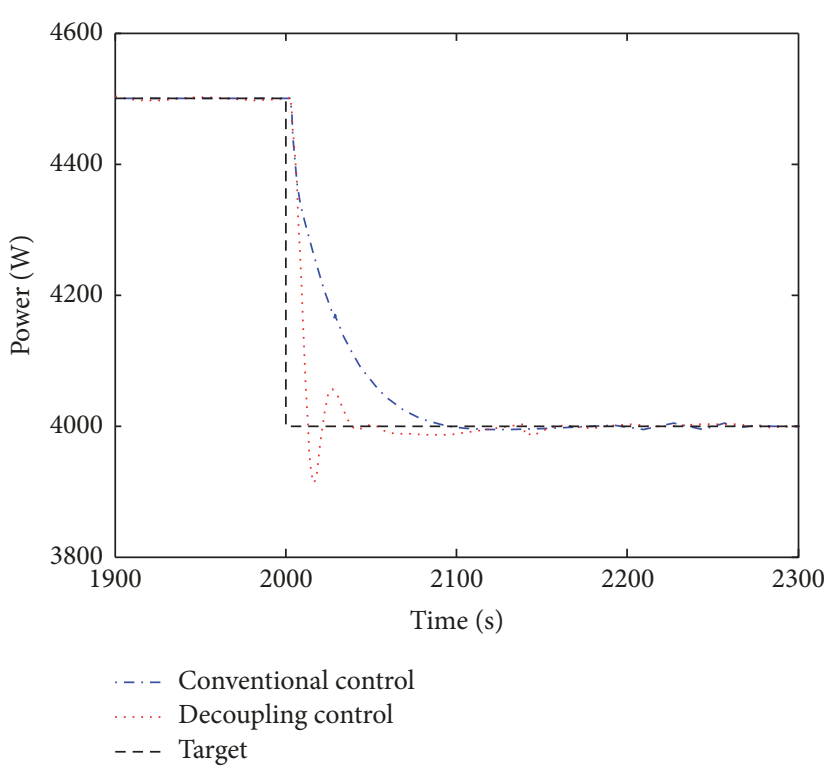

(c)

FIgURE 9: Power load following characters.

Although the stack inlet temperature fluctuates, as shown in Figures 10 and 15, the air flow rate is more than 20 times that of the AORR, making the inlet temperature reach the control target again.

Remark 2. Figure 15 shows that the air flow rate and $\mathrm{BP}$ rate of the decoupling control significantly decrease because the stabilization of the burner temperature makes it unnecessary for the stack temperature controller to utilize excessive control actuation. Decreasing the BP rate leads to a decrease in the cold air flow of the bypass heat exchangers, which positively influences the system efficiency.
Figure 16 shows the temperature distribution of the stack, air temperature responses in stack, fuel temperature responses in stack, IC temperature responses, and PEN temperature responses. All the temperatures can be maintained within $15 \mathrm{~K}$ level, despite the system power increase and decrease. According to Figure 16, the stack inlet and outlet temperatures can be kept at stable level.

Remark 3. The stack temperatures are mainly affected by the air temperatures because the air entering the stack is the main heat source for the stack operation temperature and the air flow rate is several times more than the fuel flow rate. 

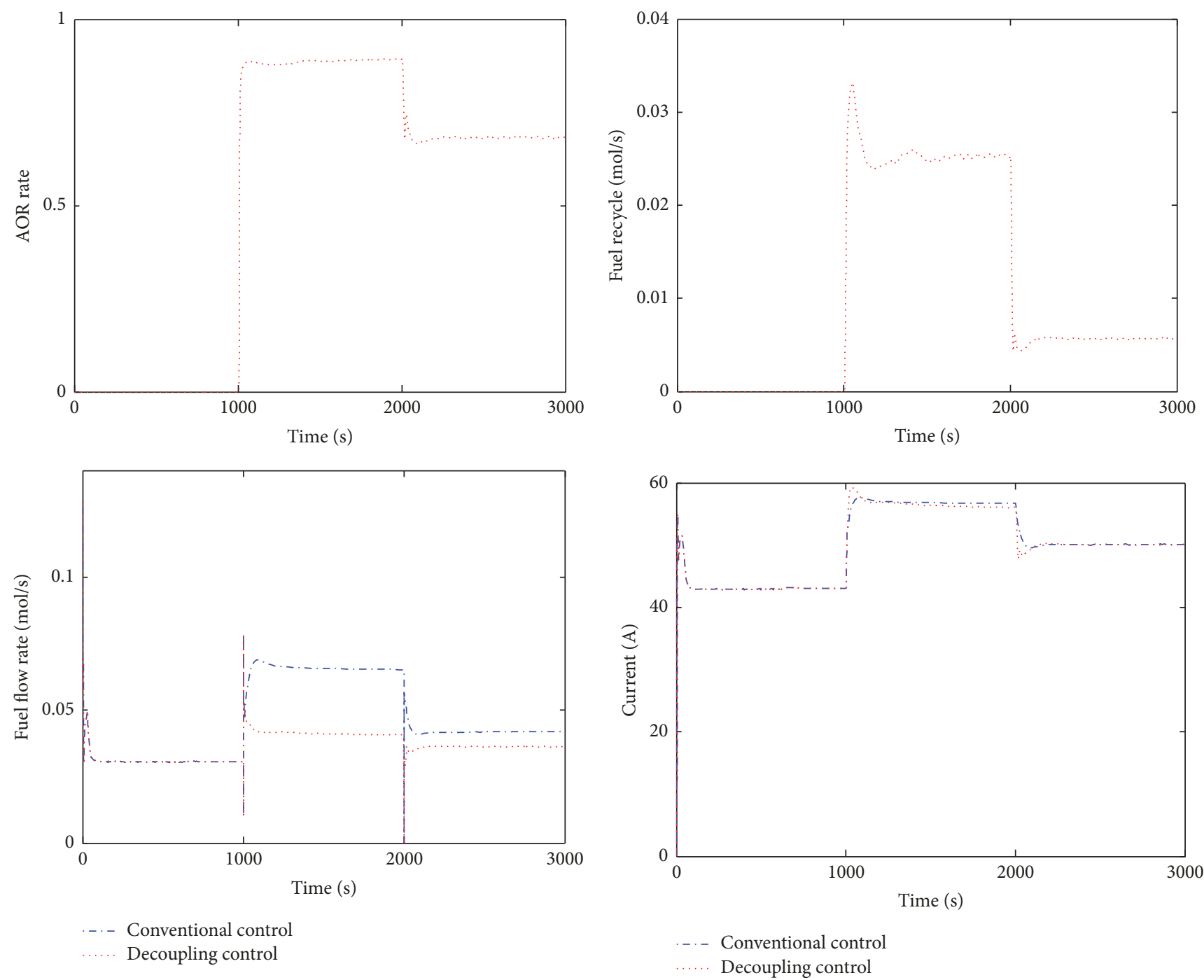

FIGURE 10: Control actuation of the decoupling power controller.

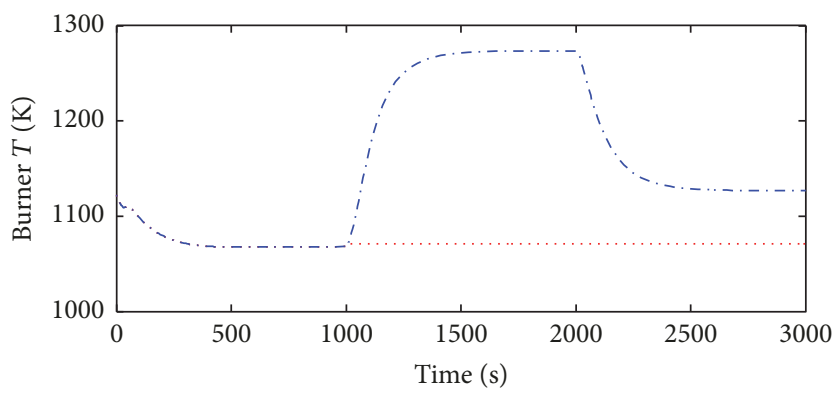

Decoupling control

- . - Conventional control

FIGURE 11: Burner temperature dynamic response.

According to Figure 16, the stack temperature distribution is nearly the linear growth along the gas flow direction. As a result, when the stack inlet temperature and the stack outlet

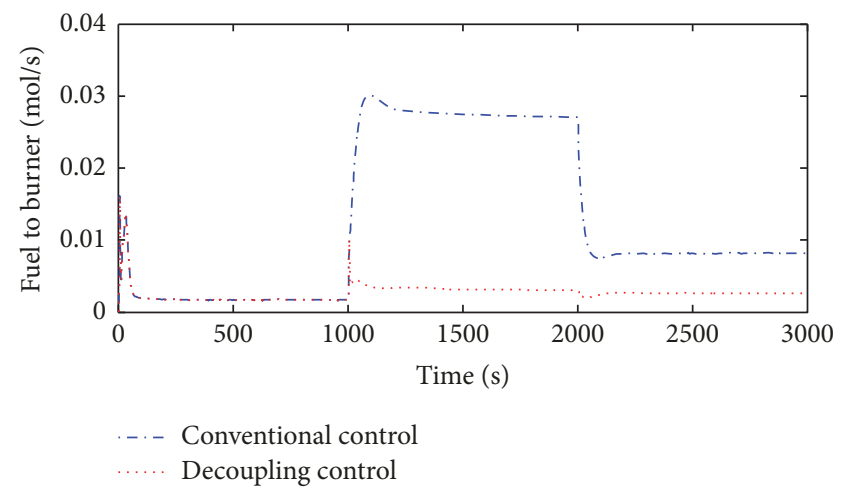

Figure 12: Fuel flow rate to burner.

temperature are controlled at the stable value, the whole stack temperature can be maintained at a constant value to some extent. 

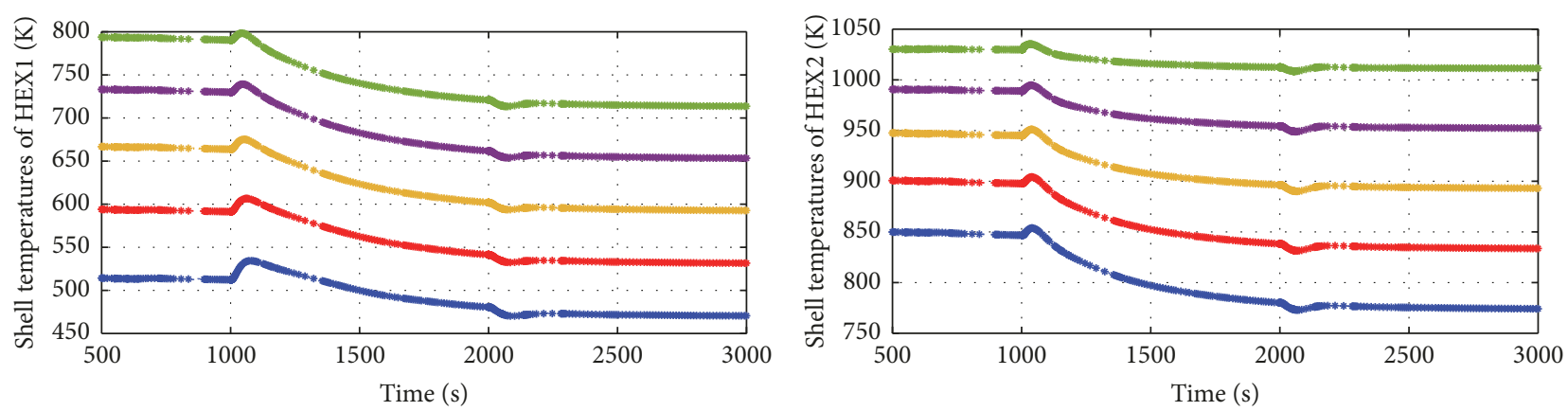

*.. Node 1
*. Node 2
*. Node 3

*.. Node 4

*.. Node 5

*.. Node 1

*.. Node 2

*.. Node 4

*.. Node 3

FIGURE 13: Heat exchangers temperature.
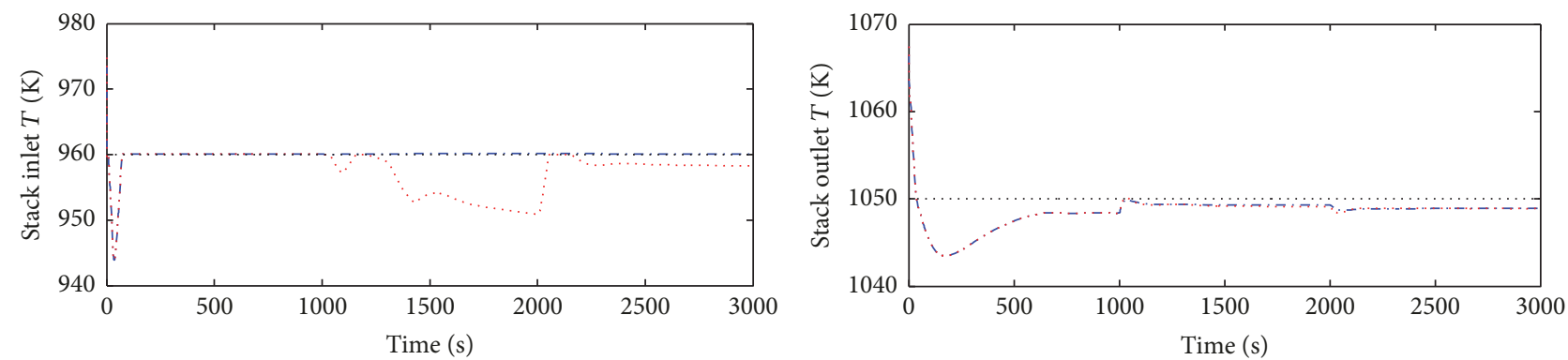

...- Conventional control

Decoupling control

Conventional control

Decoupling control

..... Target $(960 \mathrm{~K})$

..... Target (1050 K)

FIGURE 14: Stack temperature under conventional and decoupling controller.

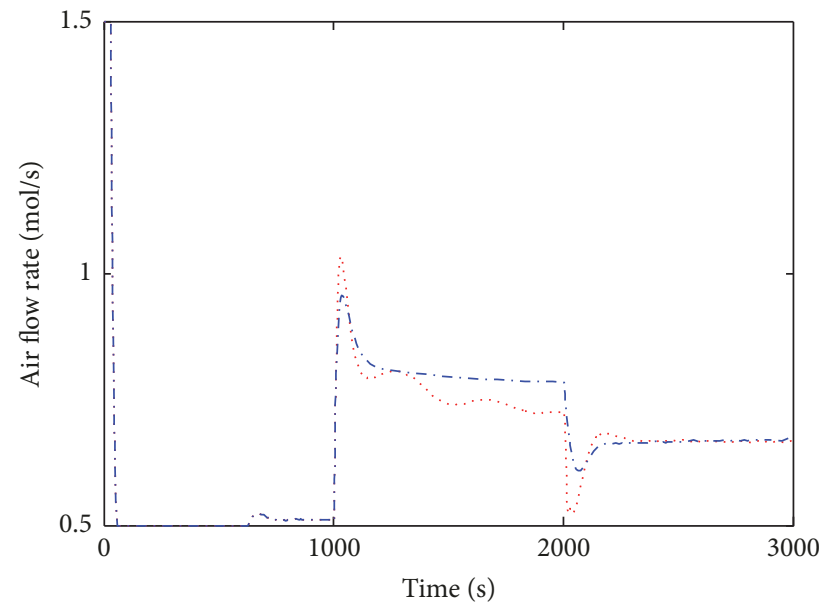

Decoupling control

- Conventional control

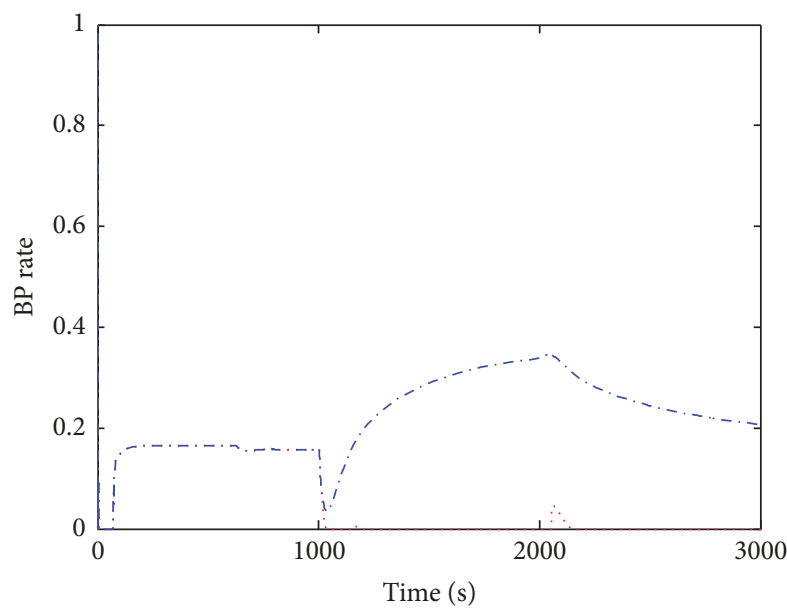

Decoupling control

.... Conventional control

FIGURE 15: Stack temperature control actuation.

4.4. FU and SE. FU and SE are two important parameters for indicating the optimal working condition of the SOFC system. In Figure 17, the FU controlled by the conventional controller is influenced by the power changes. In other words, the interaction between the power and fuel flow rate prevents the SOFC from working at a high efficiency. Therefore, the FU and SE cannot remain steady under the control of the conventional scheme. However, the decoupling controller 

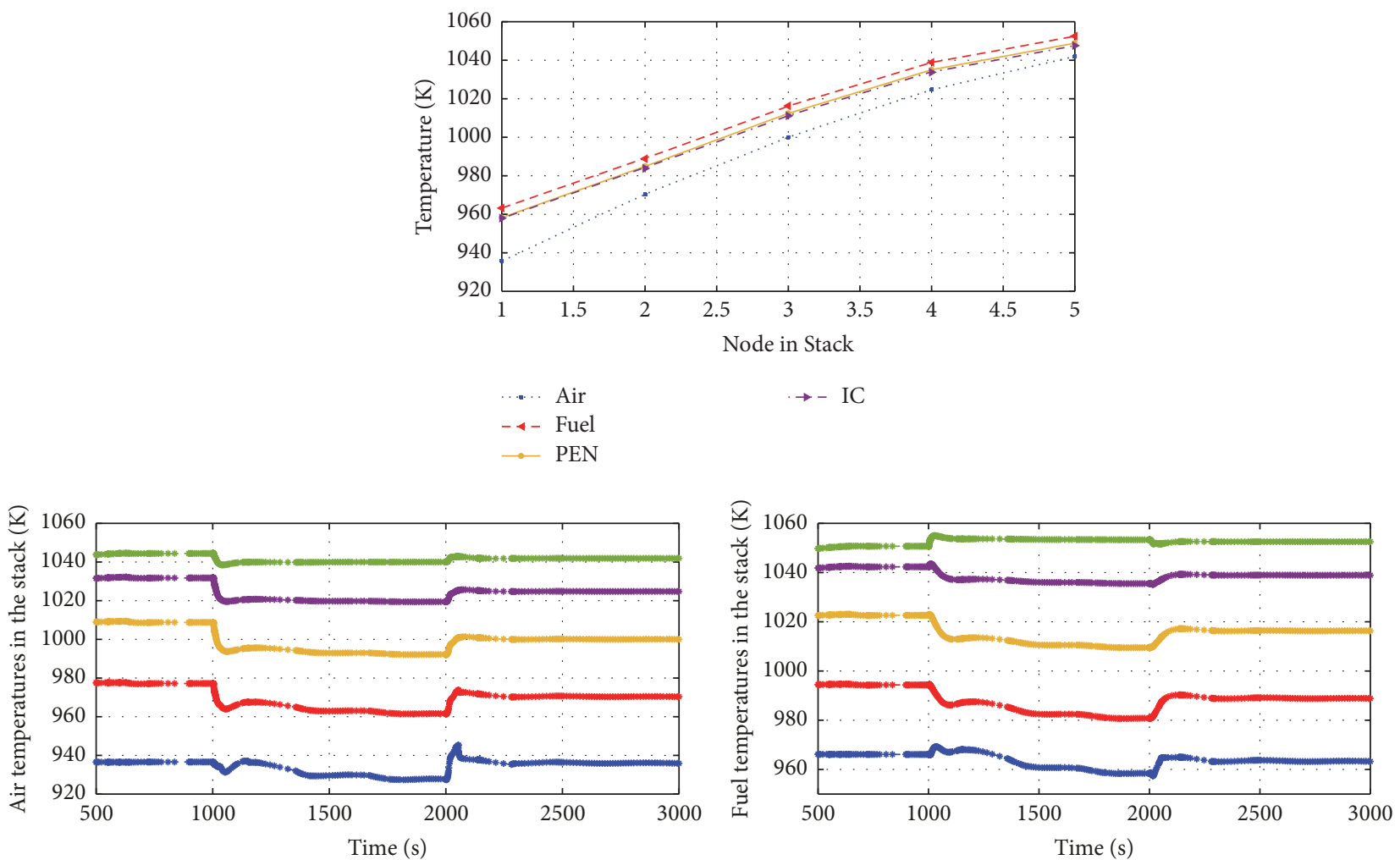
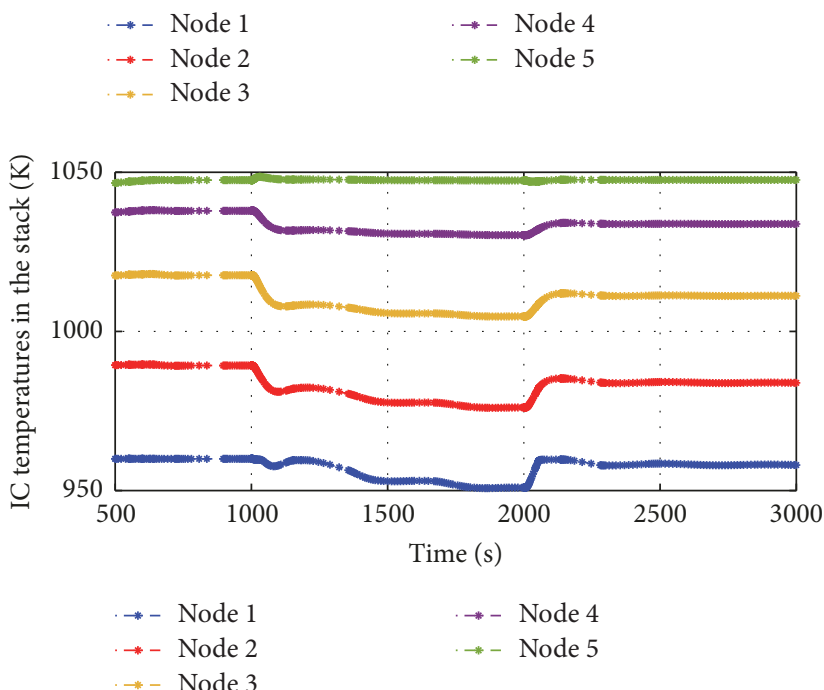

FIGURE 16: Stack temperatures. independently manages the electrical characteristics without being affected by the fuel flow. As a result, as shown in Figure 17, the FU and SE are almost maintained at a high level even as the power changes.

Figure 18 shows that the power of the AOR blower does not play an important role in the SE compared with the air blower power.

Remark 4. The FU indicates the fuel consuming rate used in stack. If more fuel is consumed in stack, it means the electrochemical reaction ratio is at a high level. The SE indicates that the power ratio can be used by the load. Figure 17 shows that the AOR controller can maintain the FU and the SE at a high level even at the power-changing condition, while the controller without AOR will not perform well. The FU first decreases at the power increase, because when the power demand increases, more fuel will be added to stack that will cause the FU decrease. For the SE, when the system power demand increases, the fuel consumed in stack will increase as well as the heat generated in stack, so more air should be added to stack to cool the temperature down and the parasitic power increase; then the SE will decrease. 

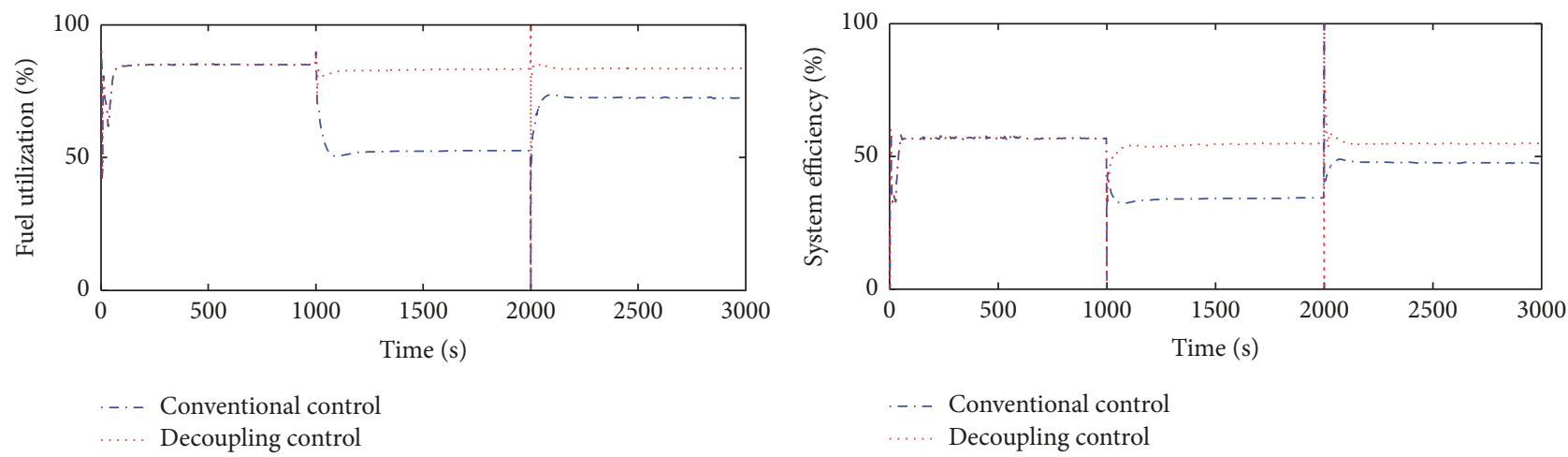

FIGURE 17: Fuel utilization and system efficiency under two controllers.
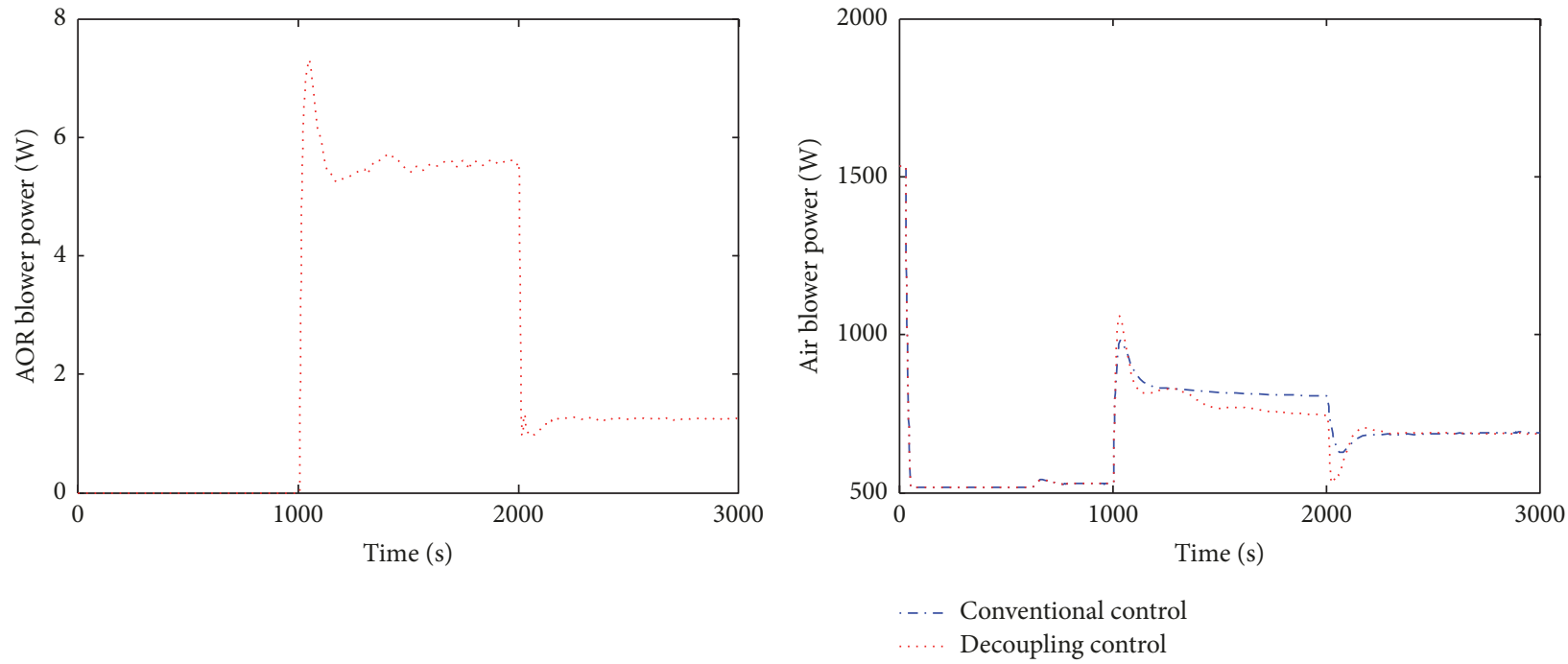

FIGURE 18: The power of AOR blower and the air blower.

Therefore, the AOR controller not only helps to control the system temperature but also controls the fuel utilization in stack and system efficiency.

\section{Discussion and Conclusion}

This study proposes an engineering-oriented decoupling controller to solve the following problems:

(1) The couplings between the electrical and thermal parameters are decoupled by the AOR-based decoupling control method. The system temperature can be independently controlled without being affected by the power changes.

(2) Fuel depletion avoidance and rapid load following. The fuel consumption time is significantly increased to avoid the fuel depletion problem. The stack fuel supply is less sensitive to the power variations.

(3) The decoupling control system can maintain the FU and $\mathrm{SE}$ at a high level even as the power changes.

Other problems, such as SOFC stack fault accommodation and fault reconfiguration control, can also be solved in the future through the decoupling-type modified control method based on the AOR. The control problems that SOFC combines with the $\mathrm{MgH}_{2}$ tank can also be investigated.

\section{Abbreviations}

C: $\quad$ Specific heat capacity, $\mathrm{kJ} \mathrm{kg}^{-1} \mathrm{~K}^{-1}$

$F: \quad$ Faraday constant $=96485 \mathrm{C} \mathrm{mol}^{-1}$

$h_{g s}$ : Convection heat transfer coefficient, $\mathrm{kW} \mathrm{m}^{-2} \mathrm{~K}^{-1}$

I: Current, A

i: $\quad$ Current density, $\mathrm{A} \mathrm{cm}^{-2}$

$N$ : Control volume mole number, mol

Q: Heat transfer, W

$R_{i}$ : Reaction rate of species $i, \mathrm{~mol} \mathrm{~s}^{-1}$

$S$ : $\quad$ Surface area of the heat transfer, $\mathrm{m}^{2}$

$T$ : Absolute temperature, $\mathrm{K}$

$W$ : Work, W

$X_{i}$ : Species mole fractions $i$

$\alpha$ : Transfer coefficient

$\rho:$ Density, $\mathrm{kg} \mathrm{m}^{-3}$. 


\section{Subscripts}

act: Activation

con: Concentration

cond: Conduction

conv: Convection

$\mathrm{H}_{2}$ : Hydrogen

$P: \quad$ Pressure

S: $\quad$ Solid

OCV: Irreversible open circuit voltage

$\mathrm{O}_{2}$ : Oxygen

L: $\quad$ Limit.

\section{Conflicts of Interest}

The authors declare that they have no conflicts of interest.

\section{Acknowledgments}

This work was supported by the National Nature Science Foundation of China (nos. 61273161 and 51777122).

\section{References}

[1] J. Lee, J. Jo, S. Choi, and S.-B. Han, "A 10-kW SOFC low-voltage battery hybrid power conditioning system for residential use," IEEE Transactions on Energy Conversion, vol. 21, no. 2, pp. 575$585,2006$.

[2] C. M. Colson and M. H. Nehrir, "Evaluating the benefits of a hybrid solid oxide fuel cell combined heat and power plant for energy sustainability and emissions avoidance," IEEE Transactions on Energy Conversion, vol. 26, no. 1, pp. 140-148, 2011.

[3] L. Schlapbach and A. Züttel, "Hydrogen-storage materials for mobile applications," Nature, vol. 414, no. 6861, pp. 353-358, 2001.

[4] E. I. Gkanas and S. S. Makridis, "Effective thermal management of a cylindrical $\mathrm{MgH} 2$ tank including thermal coupling with an operating SOFC and the usage of extended surfaces during the dehydrogenation process," International Journal of Hydrogen Energy, vol. 41, no. 13, pp. 5693-5708, 2016.

[5] H. Cao, X. Li, Z. Deng, J. Li, and Y. Qin, “Thermal management oriented steady state analysis and optimization of a $\mathrm{kW}$ scale solid oxide fuel cell stand-alone system for maximum system efficiency," International Journal of Hydrogen Energy, vol. 38, no. 28, pp. 12404-12417, 2013.

[6] C. Wang and M. H. Nehrir, "Load transient mitigation for standalone fuel cell power generation systems," IEEE Transactions on Energy Conversion, vol. 22, no. 4, pp. 864-872, 2007.

[7] C. Wang and M. H. Nehrir, "Short-time overloading capability and distributed generation applications of solid oxide fuel cells," IEEE Transactions on Energy Conversion, vol. 22, no. 4, pp. 898906, 2007.

[8] M. Fardadi, F. Mueller, and F. Jabbari, "Feedback control of solid oxide fuel cell spatial temperature variation," Journal of Power Sources, vol. 195, no. 13, pp. 4222-4233, 2010.

[9] S. A. Hajimolana, M. A. Hussain, W. M. A. W. Daud, M. Soroush, and A. Shamiri, "Mathematical modeling of solid oxide fuel cells: A review," Renewable \& Sustainable Energy Reviews, vol. 15, no. 4, pp. 1893-1917, 2011.

[10] S. Kakaç, A. Pramuanjaroenkij, and X. Y. Zhou, "A review of numerical modeling of solid oxide fuel cells," International Journal of Hydrogen Energy, vol. 32, no. 7, pp. 761-786, 2007.
[11] F. Arpino, M. Dell'Isola, D. Maugeri, N. Massarotti, and A. Mauro, "A new model for the analysis of operating conditions of micro-cogenerative SOFC units," International Journal of Hydrogen Energy, vol. 38, no. 1, pp. 336-344, 2013.

[12] A. Mauro, F. Arpino, N. Massarotti, and P. Nithiarasu, "A novel single domain approach for numerical modelling solid oxide fuel cells," International Journal of Numerical Methods for Heat \& Fluid Flow, vol. 20, no. 5, pp. 587-612, 2010.

[13] A. Mauro, F. Arpino, and N. Massarotti, “Three-dimensional simulation of heat and mass transport phenomena in planar SOFCs," International Journal of Hydrogen Energy, vol. 36, no. 16, pp. 10288-10301, 2011.

[14] R. Nishida, S. Beale, J. Pharoah, L. de Haart, and L. Blum, "Three-dimensional computational fluid dynamics modelling and experimental validation of the Jülich Mark-F solid oxide fuel cell stack," Journal of Power Sources, vol. 373, pp. 203-210, 2018.

[15] F. Arpino, N. Massarotti, A. Mauro, and L. Vanoli, "Metrological analysis of the measurement system for a micro-cogenerative SOFC module," International Journal of Hydrogen Energy, vol. 36, no. 16, pp. 10228-10234, 2011.

[16] F. Mueller, F. Jabbari, R. Gaynor, and J. Brouwer, "Novel solid oxide fuel cell system controller for rapid load following," Journal of Power Sources, vol. 172, no. 1, pp. 308-323, 2007.

[17] L. Wang and D.-J. Lee, "Load-tracking performance of an autonomous SOFC-based hybrid power generation/energy storage system," IEEE Transactions on Energy Conversion, vol. 25, no. 1, pp. 128-139, 2010.

[18] K. Sedghisigarchi and A. Feliachi, "Dynamic and transient analysis of power distribution systems with fuel cells - Part I: Fuelcell dynamic model," IEEE Transactions on Energy Conversion, vol. 19, no. 2, pp. 423-428, 2004.

[19] K. Sedghisigarchi and A. Feliachi, "Dynamic and transient analysis of power distribution systems with fuel cells - Part II: Control and stability enhancement," IEEE Transactions on Energy Conversion, vol. 19, no. 2, pp. 429-434, 2004.

[20] T. Allag and T. Das, "Robust control of solid oxide fuel cell ultracapacitor hybrid system," IEEE Transactions on Control Systems Technology, vol. 20, no. 1, pp. 1-10, 2012.

[21] A. M. Murshed, B. Huang, and K. Nandakumar, "Estimation and control of solid oxide fuel cell system," Computers \& Chemical Engineering, vol. 34, no. 1, pp. 96-111, 2010.

[22] C. Stiller, B. Thorud, O. Bolland, R. Kandepu, and L. Imsland, "Control strategy for a solid oxide fuel cell and gas turbine hybrid system," Journal of Power Sources, vol. 158, no. 1, pp. 303315, 2006.

[23] Y. Inui, N. Ito, T. Nakajima, and A. Urata, "Analytical investigation on cell temperature control method of planar solid oxide fuel cell," Energy Conversion and Management, vol. 47, no. 15-16, pp. 2319-2328, 2006.

[24] M. Sorrentino and C. Pianese, "Model-based development of low-level control strategies for transient operation of solid oxide fuel cell systems," Journal of Power Sources, vol. 196, no. 21, pp. 9036-9045, 2011.

[25] A. Pohjoranta, M. Halinen, J. Pennanen, and J. Kiviaho, "Model predictive control of the solid oxide fuel cell stack temperature with models based on experimental data," Journal of Power Sources, vol. 277, pp. 239-250, 2015.

[26] X. W. Zhang, S. H. Chan, H. K. Ho, J. Li, G. Li, and Z. Feng, "Nonlinear model predictive control based on the moving horizon state estimation for the solid oxide fuel cell," International Journal of Hydrogen Energy, vol. 33, no. 9, pp. 2355-2366, 2008. 
[27] H. Cao and X. Li, “Thermal Management-Oriented Multivariable Robust Control of a kW-Scale Solid Oxide Fuel Cell StandAlone System," IEEE Transactions on Energy Conversion, vol. 31, no. 2, pp. 596-605, 2016.

[28] B. Huang, Y. Qi, and M. Murshed, "Solid oxide fuel cell: Perspective of dynamic modeling and control," Journal of Process Control, vol. 21, no. 10, pp. 1426-1437, 2011.

[29] X.-J. Wu, Q. Huang, and X.-J. Zhu, "Power decoupling control of a solid oxide fuel cell and micro gas turbine hybrid power system," Journal of Power Sources, vol. 196, no. 3, pp. 1295-1302, 2011.

[30] D. Zhao, Q. Zheng, F. Gao, D. Bouquain, M. Dou, and A. Miraoui, "Disturbance decoupling control of an ultra-high speed centrifugal compressor for the air management of fuel cell systems," International Journal of Hydrogen Energy, vol. 39, no. 4, pp. 1788-1798, 2014.

[31] R. Peters, R. Deja, M. Engelbracht et al., "Efficiency analysis of a hydrogen-fueled solid oxide fuel cell system with anode offgas recirculation," Journal of Power Sources, vol. 328, pp. 105-113, 2016.

[32] M. Carré, R. Brandenburger, W. Friede, F. Lapicque, U. Limbeck, and P. Da Silva, "Feed-forward control of a solid oxide fuel cell system with anode offgas recycle," Journal of Power Sources, vol. 282, pp. 498-510, 2015.

[33] R. Torii, Y. Tachikawa, K. Sasaki, and K. Ito, "Anode gas recirculation for improving the performance and cost of a 5-kW solid oxide fuel cell system," Journal of Power Sources, vol. 325, pp. 229-237, 2016.

[34] M. Engelbracht, R. Peters, L. Blum, and D. Stolten, "Comparison of a fuel-driven and steam-driven ejector in solid oxide fuel cell systems with anode off-gas recirculation: Part-load behavior," Journal of Power Sources, vol. 277, pp. 251-260, 2015.

[35] R. Gaynor, F. Mueller, F. Jabbari, and J. Brouwer, "On control concepts to prevent fuel starvation in solid oxide fuel cells," Journal of Power Sources, vol. 180, no. 1, pp. 330-342, 2008. 


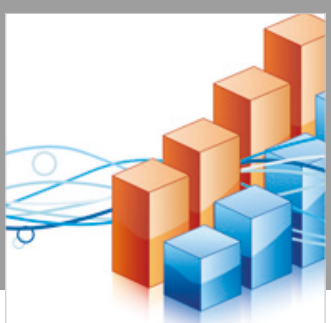

Advances in

Operations Research

\section{-n-m}
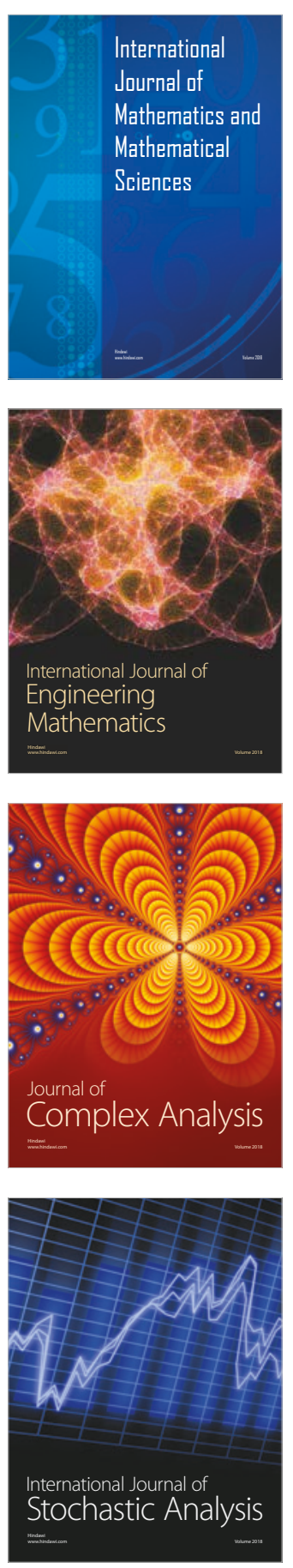
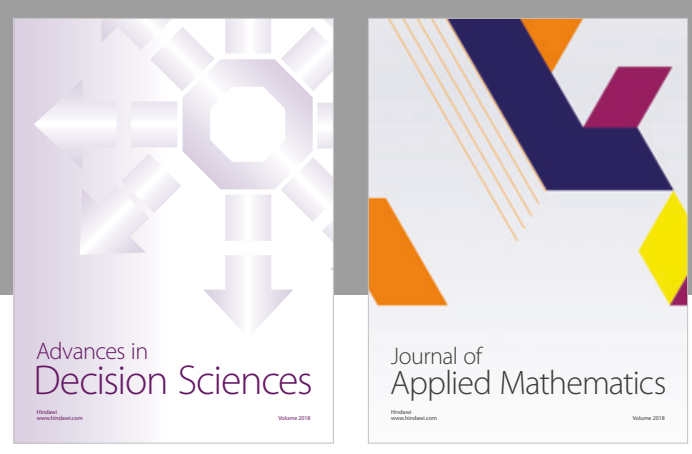

Journal of

Applied Mathematics
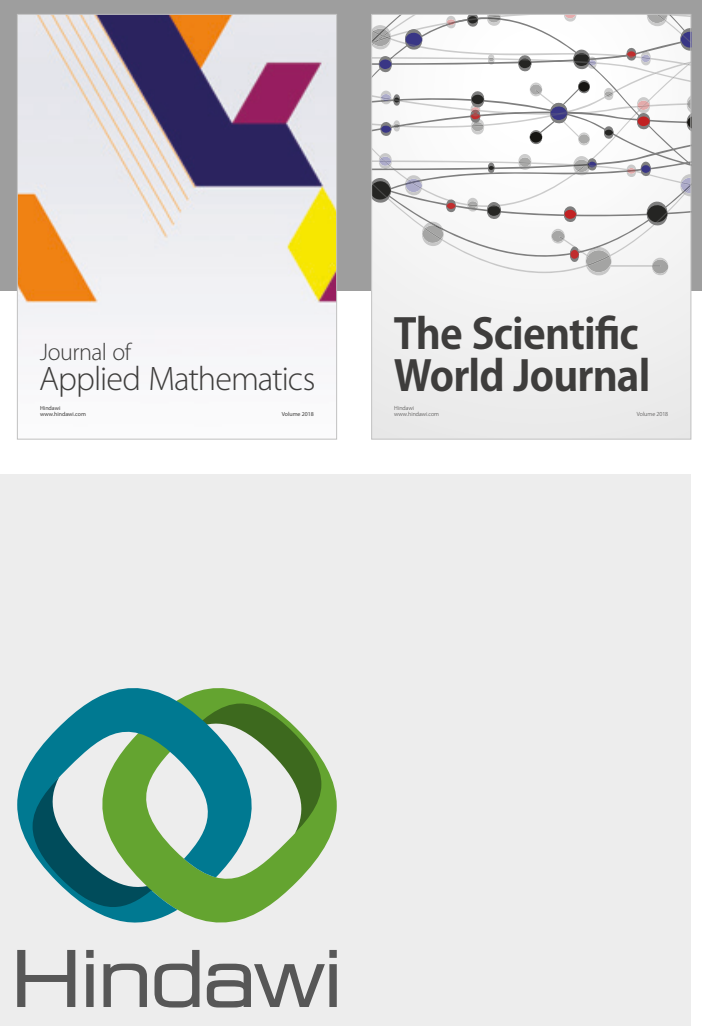

Submit your manuscripts at

www.hindawi.com

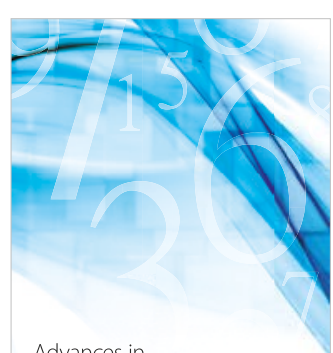

Advances in
Numerical Analysis
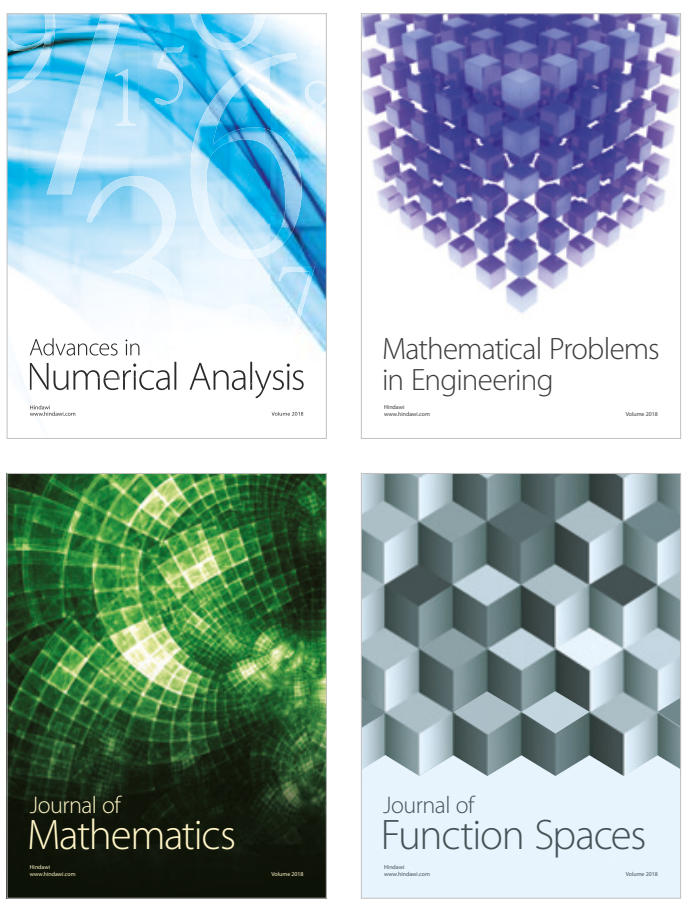

Mathematical Problems in Engineering

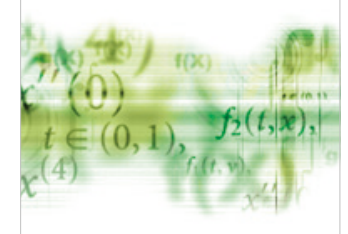

International Journal of

Differential Equations

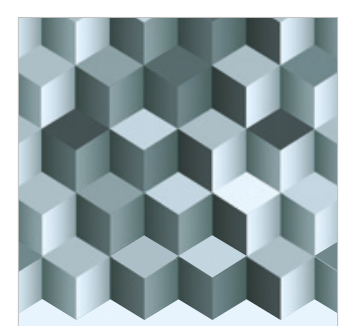

Journal of

Function Spaces

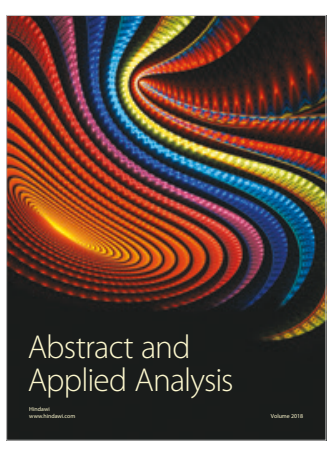

The Scientific

World Journal

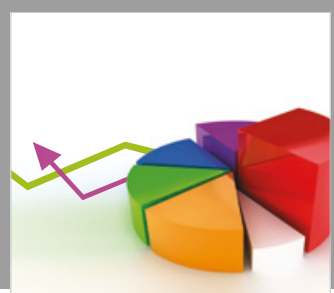

Journal of

Probability and Statistics
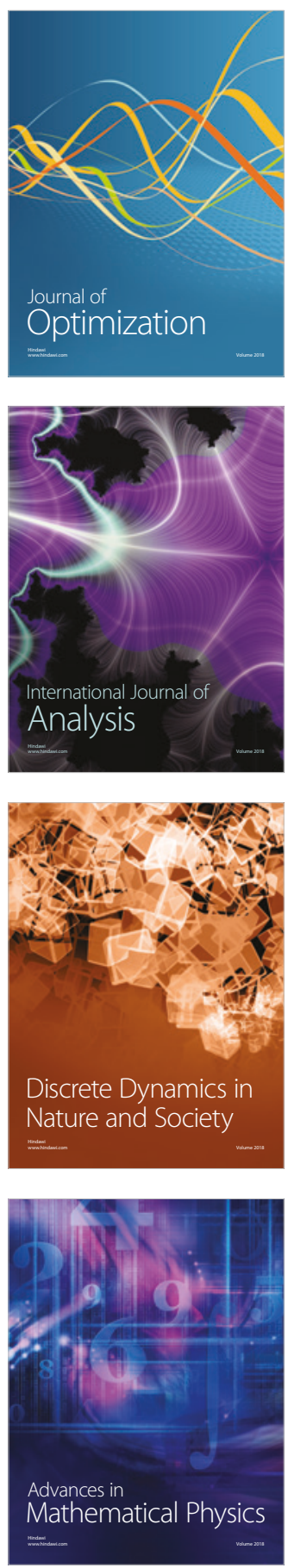